\title{
CONFLITOS POLÍTICOS LOCAIS NO DEBATE SOBRE O URBANISMO EM CAMPINAS/SP NO CONTEXTO DA INSTAURAÇÃO DO GOVERNO AUTORITÁRIO DE GETÚLIO VARGAS ${ }^{1}$
}

\author{
Daniela da Silva Santos Krogh ${ }^{2}$ \\ Ivone Salgado 3
}

DOI: 10.5752/P.2316-1752.2017v25n36p58

\section{Resumo}

Este artigo apresenta discussões sobre a remodelação de Campinas entre as décadas de 1920 e 1930, período marcado por uma turbulenta situação política no país, que afetou a questão do urbanismo na cidade. Visa discutir, por meio das fontes documentais, as interrupções e as explicações políticas suscitadas, à diferença das explicações ofi-

\footnotetext{
1. Este artigo baseia-se nas discussões presentes na tese de doutorado defendida em fevereiro de 2018 por Daniela da Silva Santos Krogh, sob a orientação da Prof. ${ }^{a}$ Dr. ${ }^{a}$ Ivone Salgado, sob o título "O debate sobre o urbanismo em Campinas: do Relatório de Anhaia Mello ao Plano de Melhoramentos Urbanos de Prestes Maia (1920-1940)", no Programa de Pós-Graduação em Urbanismo da Pontifícia Universidade Católica de Campinas. Este trabalho contou com financiamento da CAPES.

2. Bacharel e Licenciada em História pelo Centro Universitário Fundação Santo André. Mestre e Doutora em Urbanismo pelo Programa de Pós-Graduação em Urbanismo da Pontifícia Universidade Católica de Campinas. E-mail: danielaclio@yahoo.com.br

3. Doutora em Urbanismo pelo Institut d’Urbanisme de Paris - Université de Paris XII (Paris-Val-de-Marne) e pós-doutorado junto ao Istituto Universitario di Architettura di Venezia. Docente do Programa de Pós-Graduação em Urbanismo da Pontifícia Universidade Católica de Campinas. E-mail: salgadoivone@uol.com.br
} 
ciais já exploradas pela literatura sobre o tema, procurando revelar como a escolha de Prestes Maia se deu por meio de acordos políticos e estava diretamente ligada ao projeto de modernização das cidades brasileiras durante o governo de Getúlio Vargas.

Palavras-chave: Planejamento urbano. Campinas. Crise política. 
POLITICAL LOCAL CONFLICTS IN THE DEBATE ON CITY PLANNING IN CAMPINASISP IN THE CONTEXT OF ESTABLISHMENT OF GETÚLIO VARGAS'S AUTHORITARIAN GOVERNMENT

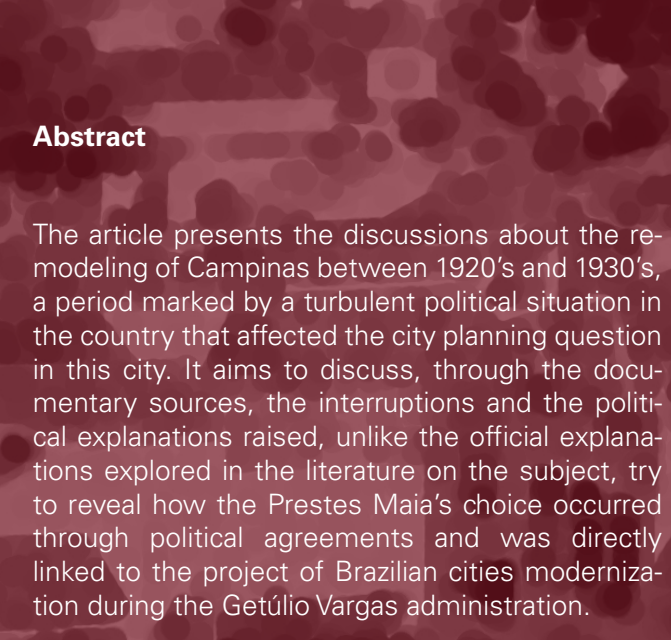

Keywords: Urban planning. Campinas. Political crisis.
CONFLICTOS POLÍTICOS LOCALES EN EL DEBATE SOBRE EL URBANISMO EN CAMPINASI SP EN EL CONTEXTO DE LA INSTAURACIÓN DEL GOBIERNO AUTORITARIO DE GETÚLIO VARGAS

\section{Resumen}

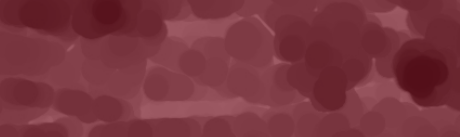

El artículo presenta las discusiones sobre la remodelación de Campinas entre las décadas de 1920 y 1930 , período marcado por una turbulenta situación política en el país que afectó la cuestión del urbanismo en la ciudad. Se trata de discutir, a través de las fuentes documentales, las interrupciones e las explicaciones politicas suscitadas, a diferencia de las explicaciones oficiales ya exploradas por la literatura sobre el tema, buscando revelar cómo la elección de Prestes Maia se dio a través de acuerdos politicos y estaba directamente ligada al proyecto de modernización de las ciudades brasileñas durante el gobierno de Getúlio Vargas.

Palabras-claves: Planeamento urbano. Campinas. Crisis política. 


\section{Introdução}

A década de 1920 foi um período conturbado no Brasil. Uma série de eventos se destaca em relação ao panorama político, como a criação do Partido Comunista, o Movimento Tenentista, o Centenário da Independência, a eleição presidencial de 1922. No panorama cultural, tem-se a Semana de Arte Moderna de 1922, em São Paulo, e todo um movimento de questionamento aos padrões culturais vigentes.

A política liberal já vinha perdendo força desde a eclosão da Primeira Guerra Mundial, sendo substancialmente agravada com a quebra da Bolsa de Nova York em 1929. Em relação ao panorama econômico do Brasil nos primeiros anos da década de 1920, há o declínio dos preços internacionais do café, a alta da inflação, crise fiscal e, mais tarde, observa-se a diversificação da produção agrícola e o desenvolvimento das atividades industriais. Houve também um expressivo crescimento das camadas médias, acompanhado de um crescimento populacional, notadamente nas áreas urbanas (FAUSTO, 1997; SKIDMORE, 2010).

Sobre a situação econômica entre 1920 e 1929, quando ocorreu a Grande Depressão, São Paulo passou por um período de transição econômica a partir do modelo agrário-exportador, dominado pela produção do café, para o desenvolvimento industrial, com a produção de bens de con- 
sumo, bem como a abertura de novos postos de trabalho e o crescimento da população urbana. E, conforme esclarece Wilson Cano: "a extraordinária expansão da economia urbana se fez notar, tanto pela expansão da infraestrutura principalmente, com a consolidação da sua rede ferroviária -, da construção civil, da indústria e dos serviços" (CANO, 2012, p. 82).

As antigas oligarquias ainda se revezavam no poder. O que se convencionou chamar de República Velha demonstrava declínio em diversos aspectos. A já conhecida "Política do Café Com Leite", na qual políticos de São Paulo e Minas Gerais se revezavam no poder federal, demonstrava há muito tempo ser permeada de conflitos. Dessa maneira, a crise política e econômica afetaria diretamente na produção do espaço urbano e determinaria as bases para o que ocorreria na década seguinte.

O ano de 1930, conturbado pela crise política, foi permeado por um clima de muitas incertezas, não somente em relação ao cenário nacional e estadual, mas também local. A tomada do poder por Getúlio Vargas trouxe consequências drásticas para administração municipal, com o fechamento das câmaras municipais em todo o país.

O cenário político brasileiro da década de 1930 interrompeu em vários momentos as discussões sobre o urbanis- 
mo em Campinas: o golpe de 1930, quando Getúlio Vargas assumiu o governo federal, desmantelou a estrutura política brasileira, com o fechamento do senado, assembleias legislativas e câmaras municipais. No âmbito estadual, os governadores foram substituídos por interventores federais e, no âmbito municipal, prefeitos foram afastados dos seus cargos. Essa situação certamente paralisou os trabaIhos nessas instâncias do poder público, o que dificultou o debate sobre o urbanismo nas cidades brasileiras. Em Campinas não seria diferente. Com o afastamento do prefeito Orosimbo Maia ${ }^{4}$ e a nomeação de José Pires Netto, o debate foi retomado com a criação da Comissão Consultiva do Plano da Cidade, em 1931.

Este artigo apresenta as discussões acerca da remodelação da cidade de Campinas/SP, iniciadas no final da década de 1920, e discute como o cenário político nacional, somado às disputas internas, notadamente a partir de 1930, conduziram e interferiram nesse debate. A fim de mostrar como a questão foi tratada na cidade, as fontes aqui utilizadas, na forma de relatórios municipais e da imprensa, forneceram os subsídios para a construção desta análise à diferença

4. Orosimbo Maia (1861-1939) foi o primeiro prefeito de Campinas, em 1908 (anteriormente, a administração municipal ficava a cargo dos Intendentes Municipais), permanecendo no cargo até 1910. Assumiu novamente a prefeitura entre 1926 e 1930. Entre 10 de abril de 1931 e 01 de outubro de 1932, foi nomeado prefeito pelo interventor estadual Capitão João Alberto Lins de Barros. 
das explicações oficiais explorada pela literatura sobre o tema (BADARÓ, 1996; SANTOS, 2002; ZAKIA, 2012, 2017).

São apresentadas ainda as diversas propostas para a remodelação de Campinas, quais sejam: O Relatório de 1929, produzido pelo professor da Escola Politécnica de São PauIo, Luiz I.R. de Anhaia Mello, a Conferência acerca do Urbanismo, do engenheiro ferroviário Carlos W. Stevenson, em 1933, e o Plano de Melhoramentos Urbanos, de 1934, de Francisco Prestes Maia, sendo este escolhido pela municipalidade.

\section{O debate sobre o urbanismo em Campinas no final da década de 1920}

A origem do debate sobre a necessidade de um plano de remodelação para Campinas pode ser identificada no Relatório de Atividades Municipais de 1927, no qual o então prefeito Orosimbo Maia argumenta sobre a necessidade de um levantamento cadastral. Nesse relatório, Orosimbo Maia afirma que naquele ano fora aberta concorrência pública para a escolha de profissionais que realizariam "o levantamento da Planta Cadastral de nossa cidade, cuja falta é sensivel (sic)" (MAIA, Relatório, 1927, p. 4).

No mesmo relatório, Maia informa que os profissionais escolhidos por meio de concorrência pública para a realização dos trabalhos de levantamento da planta cadastral de Cam- 
pinas foram os engenheiros Jorge de Macedo Vieira ${ }^{5}$ e Carl Alexander Oelsner 6 . Segundo o prefeito, os engenheiros eram "profissionaes de idoneidade technica, comprovada na execução de trabalhos do genero em São Paulo e no Rio de Janeiro. Os trabalhos deverão ser concluidos dentro de um prazo de 10 mezes (sic)" (MAIA, Relatório, 1927, p. 32).

\section{A justificativa para a realização do levantamento cadastral da cidade foi apresentada pelo prefeito no mesmo relatório}

\footnotetext{
5. Jorge de Macedo Vieira (1894-1978) formou-se em Engenharia Civil pela Escola Politécnica de São Paulo, em 1917. Iniciou sua carreira profissional como estagiário na City of São Paulo Improvement and Freehold Company Ltd., entre 1917 e 1919, empresa na qual atuava o arquiteto e urbanista inglês Richard Barry Parker, no momento em que este urbanista trabalhou na cidade de São Paulo em projetos de bairros-jardins, como Pacaembu, Jardim América e Alto da Lapa. Após o estágio, Macedo Vieira montou um escritório junto com o também engenheiro civil Mariano de Oliveira Wendell, em 1919, e, após dois anos de sociedade, abriu o seu próprio escritório técnico. Foi responsável por diversos projetos de loteamentos na cidade de São Paulo durante as décadas de 1920 e 1930, além do Distrito Industrial de Manguinhos (1927), no Rio de Janeiro. Em 1928, junto com o engenheiro Carl Alexander Oelsner, foi contratado por meio de concorrência pública pela Prefeitura Municipal de Campinas durante a gestão do prefeito Orosimbo Maia, para elaborar a Planta Cadastral da cidade, bem como o novo emplacamento, prontos em 1929. Em 1945, projetou o bairro Nova Campinas e, em 1950, o bairro Chácara da Barra, ambos em Campinas. Realizou projetos de novas cidades, como Águas de São Pedro (SP), em 1940, e Maringá (PR), em 1945. Seus trabalhos são caracterizados pelo traçado orgânico, além de incorporar os modelos garden city, city beaultiful e beaux arts em seus projetos (BONFATO, 2008).

6. Pouco se sabe sobre o engenheiro Carl Alexander Oelsner. Em 1912, atuou na cidade de São Paulo, onde realizou o levantamento topográfico nos terrenos da Cia. City of São Paulo Improvement, fundada em Londres em 1911. Não se sabe se Oelsner veio ao Brasil junto com a Cia City ou mesmo se era britânico. Foi supervisor de Macedo Vieira durante o seu estágio na Cia City entre 1917 e 1919, na qual atuou por 13 anos. Foi engenheiro-chefe da empresa The Aircraft Operating Company Ltd., especializada em fotogrametria, entre 1928 e 1931, atuando no Rio de Janeiro. Em 1939, passou a atuar por um breve período no Departamento Nacional de Estradas de Rodagem (MENDES, 2014).
} 
de 1927, no qual ele ressalta a sua futura expansão, a finalidade e os benefícios do levantamento cadastral:

Afim de evitar os inconvenientes graves a que estaria sujeita a expansão da cidade nesta phase de irradiação que se vem observando, sem um plano geral pre estabelecido, a Prefeitura determinou a abertura de uma concorrencia para a execução da planta da cidade contida no perimetro definido pela Lei 379, de 13-1226. Esse perimetro, que envolve uma area de cerca de 1.000 alqu. paulistas, comportara a provavel expansão da cidade dentro de um numero dilatado de annos, pois representa uma superficie trez vezes maior que a actualmente edificada (sic). (MAIA, Relatório, 1927, p. 32, grifos nossos).

Nesse relatório o prefeito faz menção a um "plano geral pré-estabelecido", ou seja, Orosimbo Maia, em 1927, já estava se referindo à necessidade de um plano de urbanismo para Campinas.

No dia 17 de outubro de 1928, o jornal O Estado de São Paulo publicou uma matéria na qual um candidato a vereador pelo Partido Democrático, Dr. Carlos A. Barbosa de Olivei$\mathrm{ra}^{7}$, quando questionado pelo jornal sobre melhoramentos

7. Não foi possível levantar maiores informações sobre Carlos Augusto Barbosa de Oliveira, somente que foi eleito pelo Partido Democrático nas eleições municipais de 30 de outubro de 1928, porém faleceu antes de tomar posse, sendo a cadeira ocupada por Alvaro Bastos Machado, representante do Partido Republicano Paulista (PRP), após um parecer da comissão apuradora. (O ESTADO DE SÃO PAULO, 1929, p. 6) Disponível em: <http://acervo.estadao.com.br/pagina/\#!/19290111-18132-nac-0006-999-6-not/busca/Belfort+Mattos> Acesso em: 26 set. 2017. 
da cidade e sobre suas propostas, faz algumas considerações sobre a necessidade de uma planta cadastral que havia sido encomendada pelo prefeito Orosimbo Maia:

Já está em execução o levantamento da planta cadastral da cidade, serviço importantissimo, cuja falta ha muito se fazia sentir, pois não se póde traçar um plano remodelando uma cidade sem conhecel-a em seus menores detalhes. Por falta desse serviço é que talvez a municipalidade so tenha, até hoje, conseguido meIhorar apenas pequenos trechos de ruas, e, tenha mantido para novas construcções o actual alinhamento em ruas que, tudo indica, deverão ser alargadas (sic). (O ESTADO DE SÃO PAULO apud OLIVEIRA, 1928, p. 4).

\begin{abstract}
Mais adiante, o candidato democrático critica o aspecto da cidade e argumenta sobre a necessidade de um plano efetivo de remodelação:
\end{abstract}

\begin{abstract}
Terminada essa planta, não haverá mais motivo para delongas. Mesmo que só se tenha em vista o aumento das edificações da cidade, nota-se que é urgente o estudo dos melhoramentos urbanos a introduzir para evitar não só o encarecimento gradual que o tempo vem trazendo, como para melhorar, o mais breve possivel (sic), o péssimo aspecto da cidade. (O ESTADO DE SÃO PAULO apud OLIVEIRA, 1928, p. 4).
\end{abstract}

Além de mencionar a falta de uma planta cadastral, o candidato ainda sugere que algumas ruas seriam possivelmente alargadas. Sua declaração foi uma crítica à configuração da cidade naquele momento, o incômodo da existência de 
ruas estreitas com construções nos alinhamentos das ruas em uma importante e rica cidade, mas que ainda não possuía um aspecto moderno, com largas avenidas. Barbosa de Oliveira (1928) também argumenta que, com esse instrumento técnico e um plano de remodelação, os problemas com o trânsito de veículos ligado à falta de um plano de urbanismo seria resolvido:

[...] o problema da remodelação da cidade está intimamente ligado ao do transito urbano. Possuia-mos em 1922, 174 automoveis e 1.697 carroças, sem contar outros vehiculos; apenas cinco annos depois, em 1927, vemos esses numeros elevados para 1.198 automoveis e 2.467 carroças, tendo a cidade condições de transito quasi identicas. Não é possivel pois, descurar por mais tempo de tão grave problema (sic). (O ESTADO DE SÃO PAULO apud OLIVEIRA, 1928, p. 4).

Dessa maneira, entende-se que a confecção de uma planta cadastral para Campinas era fundamental, um instrumento técnico necessário para a realização de um plano de remodelação da cidade, que, segundo o político Barbosa de Oliveira, se restringia à questão da facilitação do trânsito. Enquanto o trabalho de levantamento cadastral de Campinas estava em execução, as discussões acerca de um plano de urbanismo para a cidade estiveram em pauta na Câmara Municipal.

O ano de 1929 parece ter sido agitado na Câmara Mu- 
nicipal de Campinas, especialmente no que se refere às discussões acerca da remodelação da cidade. $\mathrm{O}$ jornal $\mathrm{O}$ Estado de São Paulo em diversos momentos noticiou, e até mesmo reproduziu na íntegra, essas discussões, cujo personagem de destaque foi por diversas vezes o vereador Belfort de Mattos $^{8}$, com a apresentação de uma proposta de remodelação da cidade. Outra figura de destaque foi o prefeito Orosimbo Maia, que, somente após diversas polêmicas que envolviam o projeto do vereador que era da oposição ao seu governo, passou a apoiar a proposta, notadamente após convidar Anhaia Mello para analisar o caso de Campinas.

Na edição de 6 de junho de 1929, o jornal O Estado de

8. Waldemar Rangel Belfort de Mattos (1897-1956), médico oftalmologista, nasceu no Rio de Janeiro e formou-se pela Faculdade de Medicina de São Paulo, em 1919. Foi vereador em Campinas entre 15 de janeiro de 1929 e 15 de outubro de 1930, pelo Partido Democrático, e defendeu a prática do urbanismo durante todo o seu mandato. O fim do seu mandato como vereador em Campinas coincide com os desdobramentos do Golpe de 1930, quando, em 1931, as câmaras municipais foram fechadas em todo o país. Fez parte da Comissão Consultiva do Plano da Cidade, em 1931, como representante da classe médica. Foi preso em 27 de novembro de 1935, em sua clínica na cidade de São Paulo, acusado de comunismo, pois havia apoiado a Aliança Nacional Libertadora (ANL) e foi membro do Partido Socialista Brasileiro. Sua prisão foi justificada por meio da lei $n^{\circ} 38$, de 4 de abril de 1935, que dispõe sobre crimes contra a ordem política e social. Parte de sua biblioteca foi também apreendida- somente os volumes correspondentes à literatura marxista. Permaneceu na prisão durante dois anos, até 1937. Em 1938, fundou os Arquivos Brasileiros de Oftalmologia. Sua ficha criminal pode ser consultada no Arquivo Público do Estado de São Paulo. Disponível em: <http://www.arquivoestado.sp.gov. br/uploads/acervo/textual/deops/prontuarios/BR_SP_APESP_DEOPS_XXX_P000960_01. pdf> Acesso em: 25 jan. 2016. 
São Paulo publicou uma matéria sob o título "A sessão de hontem - O sr. Belfort de Mattos apresenta um importante projecto sobre o urbanismo - Materia approvada na ordem do dia (dia)" (O ESTADO DE SÃO PAULO, 1929, p. 14). Nessa matéria, em que foi reproduzida a sessão da Câmara Municipal de Campinas, o vereador apresentou suas convicções acerca da necessidade de remodelação da cidade, seus conhecimentos sobre o urbanismo e um projeto de lei no intuito de concretizar suas propostas.

A sessão da câmara do dia 5 de junho de 1929, reproduzida no jornal, apresenta um discurso do vereador Belfort de Mattos, no qual ele argumenta a favor da remodelação da cidade, criticando seu estado geral:

Na sessão passada occupei vossa atenção com um problema de magna importancia para Campinas - o da sua urbanisação. Fiz varios commentarios sobre o estado actual da nossa cidade somente no que dizia respeito a Campinas como cidade de casario enxadrezado, de ruas estreitas e interminaveis, da falta de agua, da arte das suas praças e jardins e de muitos outros pontos, apenas focalizando aquillo que salta aos olhos de todos (sic). (O ESTADO DE SÃO PAULO apud MATTOS, 1929, p. 14).

Como pode-se observar na figura 1, Campinas, na década de 1920, ainda possuía feições de uma cidade do século XIX, com ruas "estreitas e intermináveis", conforme as palavras do vereador. 


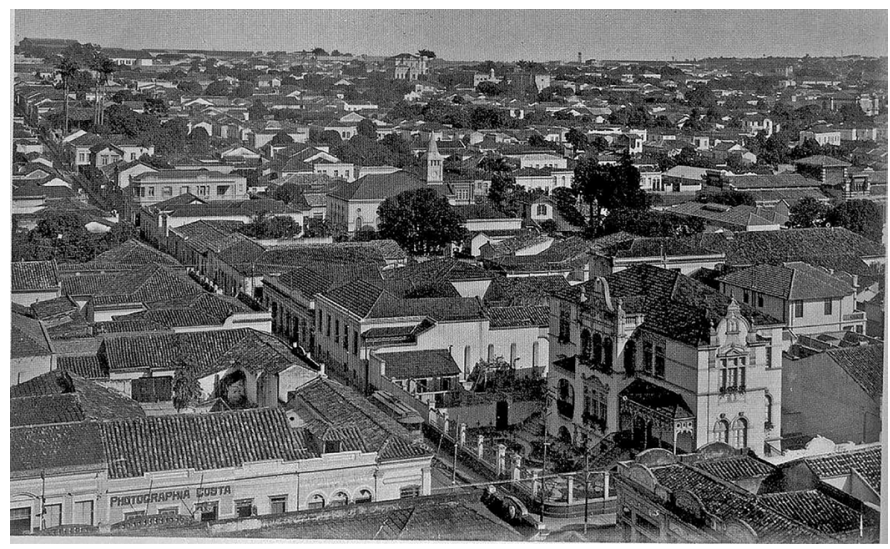

Figura 1 | Vista da Rua General Osório com Rua Regente Feijó em 1920. Fonte: Blog Pró-Memória de Campinas. Disponível em: <http://pro-memoria-de-campinas-sp. blogspot.com.br/2007/01/memria-fotogrfica-dcada-de-1920.html> Acesso em: 18 ago. 2017.

Apesar das críticas em relação ao estado geral da cidade e à permanência de ruas estreitas e, conforme dito por Belfort de Mattos, ruas "intermináveis", essa fotografia de 1920, que mostra a rua General Osório no cruzamento com a rua Regente Feijó, localizadas na área central de Campinas, revela uma ocupação organizada com um belo palacete em evidência, mas que não correspondia aos anseios de uma cidade moderna.

O vereador continuou sua defesa sobre a necessidade de remodelação de Campinas dizendo que deveria ser efetiva- 
da sob a orientação de um plano e que, nesse sentido, em relação ao urbanismo, nada ainda havia se concretizado na cidade:

[...] em materia de urbanismo nada tinha sido feito ainda em Campinas. E ninguem me podera asseverar o contrario. Se suas ruas foram alongadas aqui, espichadas acolá, tudo feito na melhor das intenções, não obedecem em absoluto a um plano geral, previamente delineado. Talvez mesmo, quem sabe taes obras municipaes possam constituir um impecilho ao plano futuro, definitivo de urbanisação. E isso não melindrará ninguem, pois, como sabeis, somente agora é que na Capital da Republica e na de S. Paulo está se cogitando de urbanisação. Em Santos, já foi levada ao plenario, na Camara Municipal, um projecto de embellezamento e não de urbanisação, como o que temos em vista (sic). (O ESTADO DE SÃO PAULO apud MATTOS, 1929, p. 14 , grifos nossos).

Belfort de Mattos acreditava que as várias obras em execução na cidade, como de ampliação e alargamento de ruas, poderiam atrapalhar um plano futuramente delineado de urbanização para Campinas. Destaca ainda o caso da cidade de Santos, onde se cogitava um projeto de embelezamento. Sobre Campinas, destaca que se visava a um projeto completo de urbanização, que almejava não somente reformas pontuais, mas que transformaria a cidade por um longo período, ou seja, um plano de longo prazo traria benefícios de longo prazo para a cidade. 
Mattos continuou seu discurso citando as palavras de Anhaia Mello, extraídas do seu livro Problemas de Urbanismo:

Peço licença para vos repetir as palavras com as quaes Anhaia Mello prefaciou o seu optimo livro "Problemas de Urbanismo" [...] "Muitos pensam que o urbanismo é apenas um problema para o engenheiro e confundem uma sciencia tão bela e vasta com a simples technica de engenharia municipal. É tambem um problema para o engenheiro, mas exige, para a sua solução perfeita e adequada, a collaboração do sociologo, do legislador, do jurista, do politico, do administrador, do economista e de todo o cidadão. Porque "urbanista" deve ser synonymo de "urbanista" no sentido de collaborador esforçado da nobre tarefa commum de melhoria da vida humana" (sic). (O ESTADO DE SÃO PAULO apud MATTOS, 1929, p. 14).

Nessa passagem, Belfort de Mattos reforça a sua defesa da adoção de um plano urbanístico completo, capaz de organizar a vida na cidade e não apenas como um conjunto de aspectos técnicos, da mesma maneira que já se executava até então. O vereador ainda apresentou algumas ideias defendidas por Anhaia Mello, especificamente sobre a participação de profissionais de áreas diversas e de todos os cidadãos como imprescindível para o seu adequado equacionamento das necessidades futuras da cidade para a implantação das reformas. Dessa maneira, pode-se observar que Belfort de Mattos mostrava um conhecimento 
especializado dos princípios da nova disciplina do urbanismo e a compreensão do seu caráter interdisciplinar.

Na sequência, o vereador ressaltou a relevância da opinião pública para o lançamento de planos de urbanismo:

A conquista da opinião publica, repitamos juntos com todos os urbanistas, é o essencial. Sem ella, nada será possivel. Precisamos adquirir a opinião publica para o bom exito da campanha em prol da urbanisação de Campinas. E todos vós sabeis, melhor do que eu, que a sciencia - arte urbanistica não é uma novidade. Data de muitos anos, de mais de um seculo mesmo. Uma cidade, desde que attinja certo numero de habitantes, o sufficiente para ser tida como tal, deve elaborar um plano de expansão e de melhoramentos (sic). (O ESTADO DE SÃO PAULO apud MATTOS, 1929, p. 14).

É importante observar que, nas considerações de Belfort de Mattos sobre Campinas, os termos "plano definitivo de urbanização, extensão, embelezamento", "sciencia - arte urbanistica" e "urbanização" são utilizados para se referenciar ao "urbanismo".

Seguindo um discurso próprio do ideário urbanístico difundido na década de 1920 por Anhaia Mello, o vereador apresenta ainda os procedimentos adotados para a implantação de um plano, destacando a prática do zoning, o que demonstra mais uma vez seu conhecimento especializado da nova ciência do urbanismo: 
Todos vos sois conhecedores da necessidade de urbanisar Campinas. Estão também ao par dos processos para tal usados em outras cidades: a desapropriação, a redistribuição, "zoning", etc., bem como dos meios de custear taes melhoramentos. E um dos problemas mais sérios do urbanismo é arranjar os meios de custear os melhoramentos projectados. O plano financeiro é tão importante quanto o plano de desenvolvimento. As fontes a que póde recorrer a Municipalidade para obter recursos indispensáveis à execução do plano são: a receita ordinaria, os emprestimos, a expropriação e as taxas especiaes (sic). (O ESTADO DE SÃO PAULO apud MATTOS, 1929, p. 14, grifo nosso).

Belfort de Mattos, em seu discurso, usa o seu conhecimento sobre o urbanismo (além de sua rede de relacionamentos na capital paulista, nesse caso, com o catedrático da Escola Politécnica de São Paulo Anhaia Mello) para que haja um convencimento por parte da câmara para a aprovação de um plano para Campinas. Ele faz muitas citações a Anhaia Mello, além de apresentar exemplos da prática em outras cidades, como São Paulo, onde ele aponta que, com o seu crescimento acelerado, a solução seria muito mais onerosa, assim como Nova York, que ele considerava o problema ainda mais complicado, até mesmo irremediável (O ESTADO DE SÃO PAULO apud MATTOS, 1929, p. 14).

No mesmo ano de 1929, o vereador Belfort de Mattos apresentou um projeto de lei na Câmara Municipal de Campinas, referente à elaboração de um plano de urbanismo; 
no entanto, o seu projeto foi rejeitado. Em 22 de junho de 1929, no jornal O Estado de São Paulo foi publicada uma matéria denominada "O Projecto Sobre O Urbanismo", a qual apresenta as razões pelas quais o então prefeito de Campinas Orosimbo Maia julgou inoportuno o projeto de urbanismo apresentado pelo vereador Belfort de Mattos. Uma das razões apontadas foi a de que a planta cadastral não estava pronta, pois era um instrumento técnico essencial para a execução dos trabalhos. Outra razão seria a falta de recursos do município para o plano (O ESTADO DE SÃO PAULO, 1929, p. 9).

As sessões da Câmara Municipal de Campinas continuariam ganhando as páginas do jornal O Estado de São Paulo. A questão da urbanização da cidade e seu principal protagonista no momento, o vereador Belfort de Mattos, estiveram em diversos momentos na ordem do dia. Meses depois, embora já estivesse pronta a Planta Cadastral de Campinas, o projeto do vereador foi definitivamente arquivado.

Na matéria do referido jornal, publicada no dia 18 de setembro de 1929, foi informado que o projeto do vereador havia sido arquivado e essa mesma matéria evidencia que o problema era de ordem política partidária, pois os vereadores que faziam parte das comissões de Finanças e Obras, encarregados da aprovação ou não do projeto, eram, em grande parte, da oposição (Partido Republicano Paulista) ao 
partido do qual Belfort de Mattos era membro (Partido Democrático).

[...] A verdade é que o projecto do sr. Belfort Mattos soffre de um mal de origem, pois foi appresentado por um representante da oposição. Ninguem de boa mente, tendo em vista a pobreza dos argumentos de que se socorrem as commissões para rejeital-o, se negará a reconhecer a procedencia dessa asserção.

Infelizmente, entre nós, ainda predominam as paixões partidarias, que impedem seja o interesse publico sobreposto sempre ás questões politicas.

Esperamos, porém, que os membros daquellas commissões e os demais vereadores situacionistas vencidos pelas razões que militam em favor do projecto do sr. Belfort Mattos, adoptem uma nobre attitude, votando pela rejeição do parecer que opina pelo seu archivamento, com o que conquistarão, por certo, o reconhecimento de quantos se interessam pelo progresso de nossa terra (sic). (O ESTADO DE SÃO PAULO, 1929, p. 9, grifo nosso).

Evidentemente, o projeto do vereador permaneceu arquivado, embora os dois lados, situacionistas e oposicionistas, defendessem a mesma causa, ou seja, a necessidade da remodelação de Campinas.

O prefeito de Campinas, Orosimbo Maia, era membro do tradicional e poderoso Partido Republicano Paulista (PRP), com maioria na câmara ${ }^{9}$. Belfort de Mattos, no entanto, era 
membro do Partido Democrático (PD), criado em 1926 na capital paulista. Segundo Antonio da Costa Santos, a referida comissão enviou o projeto ao engenheiro ferroviário Carlos William Stevenson ${ }^{10}$, o qual deu parecer favorável ao arquivamento (SANTOS, 2002, p. 241).

A criação do Partido Democrático de São Paulo reuniu indivíduos descontentes com o domínio de longa data do Partido Republicano Paulista, que ocupava posições tanto na esfera estadual como na federal. Um de seus fundadores e primeiro presidente foi o Conselheiro Antônio Prado, prefeito de São Paulo entre 1899 e 1911, político do império e antigo membro do Partido Republicano Paulista. Assim, a emergência de um novo partido político de oposição revela que, para além das questões de ordem econômica, em um momento em que o domínio estava nas mãos de uma elite agrária, em oposição à indústria em ascensão no estado de São Paulo, o Partido Democrático foi criado também contando com a presença de indivíduos ligados à oligarquia do café, nesse caso, o Conselheiro Antônio Prado.

O Partido Republicano Paulista (PRP) foi fundado em 18 de

9. A Câmara Municipal de Campinas, entre 15 de janeiro de 1929 e novembro de 1930, era composta por 11 vereadores, sendo 9 do PRP e 2 do PD, Waldemar Rangel Belfort de Mattos e José Pires Netto (ZAKIA, 2012, p. 38).

10. Carlos William Stevenson (1869-1946) formou-se engenheiro civil pela Escola Politécnica do Rio de Janeiro, em 1891. Trabalhou com engenheiro ferroviário, ocupando diversos cargos na Cia. Mogiana de Estradas de Ferro, entre 1897 e 1926. 
abril de 1873, durante a Convenção Republicana de Itu, e formado por representantes da elite da então Província de São Paulo, ou seja, grandes fazendeiros e proprietários de escravos. Um dos seus representantes, Campos Salles, seria eleito presidente da República (1898-1902). Segundo José Murilo de Carvalho, mesmo durante o império, o PRP "exibiu desde o início um grau maior de organização, e foi o único no país que demonstrou alguma força eleitoral, aliando-se, pragmaticamente, ora aos conservadores, ora aos liberais" (CARVALHO, 2014, p. 110).

Os conflitos entre esses dois partidos ganharam força dentro da política partidária paulista desde o final dos anos vinte até meados da década de 1930, pois, no caso do PD, pela primeira vez desde o final do Império, se apresentaria como um partido com oposição ideológica que diferia, em diversos aspectos, daquela do clientelismo do PRP e com forte apelo regionalista, além da oposição ao governo de Washington Luís, do PRP. Entretanto, o PD não aparece como representante de setores novos, como os grupos industriais e financeiros e a classe média, mas com uma posição ideológica que ansiava a reforma política e o anti-industrialismo (FAUSTO, 2011, p. 49; WOODWARD, 2004, p. 42).

Logo após a fundação do PD na capital paulista, o partido espalhou-se por todo o estado de São Paulo, com a abertu- 
ra de diretórios pelos diversos municípios, e em Campinas ganharia também muitos filiados, que passaram a ocupar as fileiras na Câmara Municipal, mesmo sendo a minoria, como o já citado Belfort de Mattos e o futuro prefeito da cidade, José Pires Netto. ${ }^{11}$

Como se pode observar, na matéria anteriormente mencionada, foi instaurada uma espécie de conflito no interior na Câmara Municipal de Campinas, com o arquivamento do projeto de urbanismo do vereador Belfort de Mattos, representante do $\mathrm{PD}$, a partir da denúncia feita pelo autor da matéria.

Sendo o urbanismo uma ciência operativa da política, uma proposta de remodelação da cidade foi transformada nesse meio tempo em objeto de disputas políticas na câmara.

$\mathrm{O}$ arquivamento do projeto do vereador Belfort Mattos, como visto, por motivos políticos, como uma proposta da

11. Campinas contava com um diretório e um subdiretório do Partido Democrático no Arraial de Souzas, conforme consta na Lista de Diretórios municipais definitivos de 1928, presente no Acervo digital do Arquivo Público do Estado de São Paulo. Disponível em: <http://www.arquivoestado.sp.gov.br/site/acervo/repositorio_digital/partido_democratico> Acesso em: 31 jul. 2017. Na Lista da composição dos diretórios da capital paulista e do interior, apresentada em ordem alfabética, o diretório de Campinas era formado por oito membros em 1928: Dr. Francisco de Araujo Mascarenhas, Dr. Antonio Augusto da Costa Carvalho, Dr. Carlos A. Barboza de Oliveira, Idalecio Teixeira de Camargo, Joaquim Teixeira Penteado Neto, Alexandre L. de Almeida Barros, Francisco Murtinho de Castro e Dr. Renato Egydio de Souza Aranha. Disponível em: <http://www.arquivoestado.sp.gov.br/uploads/acervo/textual/partido_democratico/BR_SP_APESP_IHGSP_ PD_083_004_002.pdf> Acesso em: 31 jul. 2017. 
oposição rejeitada pelos políticos da ocasião, não impediu que as discussões sobre a necessidade de remodelação de Campinas continuassem na pauta da câmara municipal. Após a polêmica, a visita de Anhaia Mello, a convite do prefeito Orosimbo Maia, impulsionaria a decisão para a contratação de um plano e de um urbanista.

\section{O contexto político na década de 1930}

Entre as propostas de Belfort de Mattos, o relatório de Anhaia Mello e a contratação de Prestes Maia, uma crise política e institucional interrompeu a questão do urbanismo em Campinas: a chamada "Revolução de 1930", o golpe que culminou na tomada do poder federal por Getúlio Vargas. Nesse clima de incertezas, em 1930 as câmaras municipais de todos os municípios brasileiros foram fechadas e os governadores foram substituídos por interventores federais escolhidos por Vargas, que passaram a nomear os prefeitos nas cidades conforme os interesses políticos da ocasião.

Mesmo que a administração de Campinas tenha continuado durante um breve período com o prefeito Orosimbo Maia, os vereadores perderam seus cargos, o que levou a um esvaziamento do debate acerca da implementação de um plano de urbanismo na cidade. Anhaia Mello, que já havia visitado a cidade em 1929 e realizado um relatório sobre o urbanismo cuja contratação era cogitada em Cam- 
pinas, foi nomeado prefeito da cidade de São Paulo, entre 6 de dezembro de 1930 e 25 de julho de 1931 (SANTOS, 2002, p. 334).

Embora a nomeação de Anhaia Mello para o cargo de prefeito de São Paulo seja a explicação recorrente na historiografia local (BADARÓ, 1996; SANTOS, 2002; ZAKIA, 2012, 2017) para que o engenheiro não tenha elaborado o plano definitivo para Campinas, os motivos parecem ter sido outros: sua filiação política em apoio ao governo da ocasião e em oposição ao partido à frente da administração municipal em Campinas pode ser a explicação mais razoável para a sua não contratação, pois Anhaia Mello era membro do PD, assim como o vereador Belfort de Mattos, ambos da oposição ao PRP, de Orosimbo Maia e da maioria dos antigos vereadores.

Além do golpe de 1930, a guerra paulista de 1932 também viria a afetar diretamente as decisões da administração municipal, já fragmentada pelo fechamento das câmaras e a troca constante de prefeitos nomeados por interventores federais. A filiação política desses agentes também era um obstáculo no momento das discussões sobre a remodelação da cidade: oposicionistas e situacionistas estiveram ora em disputa, ora em concordância sobre a questão do urbanismo. 


\section{A breve retomada do debate: A Comissão Consultiva do Plano da Cidade de 1931}

O Relatório para Campinas, produzido por Anhaia Mello em 1929, contém as bases para a elaboração de um plano de urbanismo, no qual o engenheiro fornece orientações sobre a legislação, o prazo necessário para a implantação do plano, o zoning, o civic survey, a ideia do comprehensive planning, ou plano abrangente, entre outros aspectos, e sempre fazendo referência ao ideário urbanístico internacional, notadamente o norte-americano. Nesse sentido, Anhaia Mello argumenta que, para a consecução de um plano de urbanismo, era necessária a criação de uma Comissão do Plano da Cidade como um primeiro passo para o equacionamento dos problemas urbanos (MELLO, Relatório, 1929, p. 12).

Segundo Sarah Feldman (2012), suas ideias estavam inseridas em um contexto mais amplo de modernização da administração pública no Brasil. Desde o final da década de 1920, Anhaia Mello defendia o modelo administrativo norte-americano para a gestão municipal de maneira geral e para as questões do urbanismo, em particular. Em sua produção textual das décadas e 1920 e 1930, é possível identificar sua ideia de desvinculação das questões do urbanismo da política, quando o urbanista defende a formação da Comissão do Plano (FELDMAN, 2005, p. 48). 
Anhaia Mello defendia que a Comissão do Plano seria composta por representantes da sociedade civil e deveria estar desvinculada do poder municipal. De acordo Feldman:

\begin{abstract}
Anhaia Mello defendia a Comissão como uma instância de caráter definitivo e não transitório, com autonomia do poder municipal com poderes absolutos em relação ao plano. Os membros representantes do governo deveriam estar em minoria "a fim de não transformar a Commissão (sic) em sucursal da Administração Municipal" (MELLO, 1928, p. 286 apud FELDMAN, 2012, p. 63)
\end{abstract}

No entanto, desvincular o urbanismo da política com a criação de comissões que supostamente estariam fora dessa esfera era - e ainda o é - praticamente impossível. É uma posição contraditória, pois se para a realização de planos é necessária a criação de leis que passam por aprovação do poder público, como desvincular o urbanismo da política? No caso de Campinas, que aqui interessa mais de perto, viu-se o arquivamento de um projeto de urbanismo por questões de política partidária, apresentado por um vereador da oposição, sob a justificativa da falta de recursos do município e pelo fato de a planta cadastral ainda não estar pronta, muito embora o projeto do vereador Belfort de Mattos, pelo menos no que diz respeito ao discurso sobre o urbanismo, representasse uma proposta ligada às filiações de Anhaia Mello, dentro do que se discutia não somente em São Paulo, mas internacionalmente. 
As comissões eram indicadas pelo prefeito, contendo nomes tanto de vereadores como de representantes de empresas e instituições atuantes na cidade. Portanto, essas comissões não eram totalmente desvinculadas da política: eram mistas, ou seja, serviam tanto à ação política, com a presença de vereadores e do prefeito, como à iniciativa privada, representantes de classe, da sociedade civil etc.

No referido relatório para Campinas, Anhaia Mello fornece informações sobre como a Comissão Consultiva do Plano da Cidade deveria ser constituída, assim como quem dela deveria fazer parte. Nesse sentido, o engenheiro argumenta que a comissão deveria ser constituída pelo prefeito e vereadores, representantes das Cias. Paulista de Estradas de Ferro, Mogiana e Sorocabana (ferrovias que operavam em Campinas), empresas de serviços coletivos, alguns "cidadãos eminentes" de Campinas e jornalistas locais (MELLO, Relatório, 1929, p.12).

Seguindo as orientações de Anhaia Mello, foi oficialmente criada a "Commissão de Urbanistas", por meio do Decreto $n^{\circ} 11$, de 19 de fevereiro de 1931, durante a gestão do prefeito nomeado José Pires Netto (27/10/1930-10/04/1931). Essa comissão foi criada na forma de um órgão consultivo da Prefeitura Municipal de Campinas para tratar dos assuntos relacionados ao plano de remodelação da cidade. Entretanto, a referida comissão funcionou por um curto período, 
entre fevereiro e abril de 1931, após o afastamento do prefeito e presidente da comissão Pires Netto e renúncia da maioria dos seus membros em solidariedade a ele.

O prefeito, membro do PD, que até então apoiava o governo provisório de Getúlio Vargas, não poderia continuar no cargo, pois o seu partido havia publicado nos jornais um manifesto contra o interventor do estado de São Paulo, João Alberto, entre os dias 6 e 8 de abril de 1931. Nesse sentido, a renúncia dos membros da comissão é explicada por motivos de ordem política.

A decisão sobre o afastamento de Pires Netto do cargo de prefeito foi tomada durante uma reunião no diretório do PD em Campinas, seguida pela oficialização por meio de um telegrama enviado pelo prefeito ao interventor, com o pedido de demissão em 7 de abril de 1931. O jornal O Estado de São Paulo, em sua edição de 8 de abril de 1931, publicou o ofício de Pires Netto enviado ao interventor João Alberto, no qual há a justificativa principal: "Acontece, entretanto que, filiado ao Partido Democratico, na hora actual, em obediência á disciplina partidaria, julga do seu dever declinar de tal honra. Assim, pelo presente, vem pedir a exoneração do cargo que exerce (sic)" (O ESTADO DE SÃO PAULO, 1931, p. 4).

Sobre o rompimento oficial do PD com o interventor João 
Alberto em abril de 1931, Maria Lígia Coelho Prado afirma que:

Quando se tenta compreender o rompimento, nota-se que havia dois pontos significativos: o primeiro consistia na própria disputa pelo poder, e o segundo referia-se à crença de que João Alberto tinha simpatias pelo comunismo e estava abrindo um precedente perigoso com suas atitudes muito "paternais" com relação à classe operária. Este ponto nos parece fundamental, pois as diversas frações da classe dominante, representadas no Partido Republicano Paulista e no Partido Democrático, confirmavam a mesma postura e apresentavam justificativas semelhantes nas suas investidas contra João Alberto. (PRADO, 1986, p. 104).

Nos dias 5 e 6 de abril de 1931, o PD publicou nos jornais o rompimento com o interventor federal João Alberto, criticando duramente sua administração, que, segundo o manifesto, era marcada pela supressão da liberdade ao realizar prisões de membros do PD, a criação da Repartição de Censura à Imprensa, desperdício de dinheiro público, criação de cargos desnecessários e total incompetência administrativa. O Manifesto, assinado por vários líderes do $\mathrm{PD}$, contou também com a assinatura de Belfort de Mattos, como representante do diretório de Campinas (MANIFES-

12. O Manifesto do Partido Democrático contra o interventor João Alberto foi assinado em 24 de março de 1931, mas somente foi oficialmente lançado em 6 de abril do mesmo ano, tanto no jornal da agremiação, O Diário Nacional, como nos demais periódicos que circulavam no período, como, por exemplo, O Estado de São Paulo. 


\section{TO DO PARTIDO DEMOCRÁTICO, 1931) ${ }^{12}$.}

Diante dessa situação, os trabalhos da Commissão Consultiva do Plano da Cidade foram encerrados em 09 de abril de 1931, ficando um interregno de quatro anos até a formação de uma nova comissão de urbanismo, que ocorreu em 19 de setembro de 1935, quando se sucedeu a posse da segunda comissão.

O período entre 1931 e 1932 foi muito conturbado, havendo trocas de prefeitos e também de interventores federais no estado de São Paulo. Em 1932, eclodiu o "Movimento Constitucionalista", que, nos seus três meses de duração, foi o maior conflito armado do Brasil e que somente acabaria com a rendição das tropas paulistas, fortemente combatidas pelas tropas federais. Vale destacar que o estado de São Paulo foi o único estado da federação que não apoiava o governo provisório de Vargas, exceto pelos membros do PD, cujo apoio não durou por muito tempo. Este também se configura como um dos fatores que encerrariam as discussões do urbanismo em Campinas naquele momento.

Com o afastamento de José Pires Netto, Orosimbo Maia foi nomeado novamente para o cargo de prefeito, entre 10 de abril de 1931 e 1 de outubro de 1932, sendo substituído no mesmo dia pelo tenente-coronel Elias Coelho Cintra e, horas depois, por Alberto Cerqueira Lima, nomeado até 7 
de setembro de 1933. No entanto, durante o período que vai da gestão de Orosimbo Maia, entre abril e outubro de 1932, até o final da gestão de Alberto Cerqueira Lima, em setembro de 1933, nenhuma inciativa foi tomada em relação ao urbanismo em Campinas (SANTOS, 2002, pp. 259269).

O debate sobre a contratação de um plano de urbanismo para Campinas foi esvaziado. A discussão seria retomada junto à comunidade técnica local em 1933, quando o engenheiro Carlos William Stevenson proferiu uma conferência no Rotary Clube da cidade sobre o tema, argumentando sobre a necessidade de sua remodelação. A proposta do engenheiro privilegiava basicamente a remodelação do sistema viário, mas o zoning, aspecto essencial de um plano urbanístico, só foi mencionado rapidamente no final dessa conferência. Embora o engenheiro não tenha desenvolvido esse aspecto no decorrer na sua proposta, mesmo que de forma muito resumida, aponta para a questão do zoning ao mencionar a localização das diversas atividades e usos urbanos. Para Santos, essa proposta reduzia o conceito mais amplo de plano de conjunto defendido por Anhaia Mello para Campinas (SANTOS, 2002, p. 262).

A conferência de Stevenson, no dia 17 de novembro de 1933, devolveria à pauta a questão da remodelação da cidade meses antes da contratação de Prestes Maia, que se 


\section{A Conferência de Carlos W. Stevenson (1933) e as propostas de Prestes Maia (1934): novas propostas e antigas disputas políticas}

Na conferência realizada no Rotary Clube de Campinas, em 17 de novembro de 1933, o engenheiro Carlos W. Stevenson apresentou uma proposta viária, visando ao alargamento de algumas ruas na área central da cidade. Para a construção de sua proposta, o engenheiro se baseou no livro recém-publicado de Jean Raymond ${ }^{13}$, engenheiro civil e urbanista francês, Guide Pratique de I'Urbaniste ${ }^{14}$.

Stevenson propõe uma série de intervenções viárias na área central de Campinas, com o alargamento de algumas ruas, que seriam transformadas em avenidas e interligadas com as estações ferroviárias. Nessa conferência, é possível perceber que tudo indicava que a área central da cidade, já

13. Jean Raymond, engenheiro civil e urbanista, foi o primeiro estudante do Instituto de Urbanismo da Universidade de Paris a apresentar uma tese sobre o Marrocos, sob a direção de Jacques Greber, em 1931. O conteúdo de sua tese, intitulada Station balnéaire Agadir-Plage, Côte occidentale du Maroc, pode ser encontrado no livro citado por Carlos Stevenson, Guide Pratique de I'Urbaniste, publicado em 1933, em Paris (FREY, 2010).

14. A proposta do livro de Jean Raymond era ser um instrumento de trabalho destinado ao planejamento das cidades coloniais. A obra divide-se em duas partes: a primeira, utilizada por Carlos Stevenson, se referia ao planejamento de uma cidade ferroviária fictícia, onde não há a preocupação com o relevo e a topografia, e a segunda parte, um estudo sobre a cidade litorânea próxima de Agadir, no Marrocos, então Protetorado da França (ZAKIA, 2012, p. 54). 
densamente ocupada e construída, seria inteiramente remodelada a partir de um plano viário e a designação de um centro comercial. Já a aplicação do zoning seria destinada à área de expansão da cidade, para além da Avenida de Contorno, conforme seria proposto por Prestes Maia em 1935.

A leitura de sua proposta para a remodelação de Campinas revelou indícios de uma aproximação das ideias defendidas por Prestes Maia e que ele seria o urbanista responsável pela elaboração do plano para Campinas. A posição que esse engenheiro ocupava na administração municipal como presidente do Conselho Consultivo da cidade pode ter sido decisivo para essa escolha. Esse mesmo engenheiro sugeriu o arquivamento do projeto de urbanismo apresentado pelo vereador do PD Belfort de Mattos em 1929, o que deixou claro que as disputas políticas entre situacionistas e oposicionistas naquele momento afetaram a discussão sobre o urbanismo em Campinas.

Em abril de 1934, o engenheiro Francisco Prestes Maia foi contratado para elaborar um plano de remodelação para Campinas, após discussões entre conselheiros municipais e o interventor federal no estado de São Paulo, Armando de Salles Oliveira, autorizar a Secretaria de Viação e Obras Públicas a negociar os serviços de consultoria de Prestes Maia com a Prefeitura de Campinas, em abril de 1934, sua contratação foi firmada para elaborar o plano de urbanismo 
da cidade (SANTOS, 2002, p. 273).

A presença de Prestes Maia em Campinas também coincide com a nova Constituição Federal, promulgada em 16 de julho de 1934. Skidmore considera a Constituição de 1934 como um produto híbrido, pois: "Como documento jurídico, deu realidade, em grau notável, aos ideais tanto do liberalismo político como do reformismo socioeconômico" (SKIDMORE, 2010, p. 52).

O que interessa mais de perto é o fato de que a Constituição de 1934 definiu as regras de atuação na questão do urbanismo nas esferas públicas, criando um novo aparato técnico-burocrático. O documento autorizava os governos estaduais a criar um órgão de assistência técnica e fiscalização das finanças municipais, ou seja, os Departamentos das Municipalidades, com a função de prestar assistência técnica e fiscalizar as finanças dos municípios. O órgão também teria como função a intervenção nos municípios no caso de impontualidade ou falta de pagamento de suas dívidas adquiridas junto aos estados (CONSTITUIÇÃO, 1934, ART. 13, § $3^{\circ}-\S 4^{\circ}$ \%.

Nesse sentido, a Constituição de 1934, apesar de atender aos interesses das elites do período, não atingiu um equilíbrio entre forças políticas opostas, ou seja, entre políticos identificados como liberais e grupos ligados ao reformismo 
socioeconômico. O que ocorreu nos anos que se seguiram foi uma radicalização do sistema político e do Estado no Brasil, tal qual estava ocorrendo na Europa com os regimes totalitários. Esse fato se confirma com o golpe do Estado Novo, em 1937.

Prestes Maia apresentou sua proposta para Campinas em 1934, conforme publicado no Relatório de 1934 do prefeito José Pires Netto, que havia sido novamente nomeado prefeito (17/08/1934-03/06/1936). Na sua "Exposição Preliminar", Prestes Maia aponta uma série de aspectos que compõe um plano de urbanismo. A segunda parte da sua proposta foi apresentada em 1935, no relatório municipal, denominada Rascunho da Exposição Preliminar.

A fim de discutir as propostas para a remodelação de Campinas, uma nova comissão foi criada, por meio do Decreto de $n^{\circ} 135$, de 12 de agosto de 1935, denominada Comissão de Urbanismo de Campinas. Prestes Maia esteve presente nas reuniões da referida comissão, apresentando suas propostas para Campinas e insistindo na sua participação para a definição de um plano definitivo para a cidade.

Sobre o plano esquemático, o urbanista destaca que este não possuía um caráter de projeto, tampouco de uma proposta formal, ou seja, seria apenas um esboço, pois o plano de remodelação, pelo o que ele sugere, seria construído 
em conjunto com a Comissão de Urbanismo e de acordo com as necessidades e aspirações da cidade. O urbanista utilizou a Planta Cadastral de 1929 para apresentar sua proposta de plano material, isto é, o plano viário a partir de traços muito simples (fig. 2):

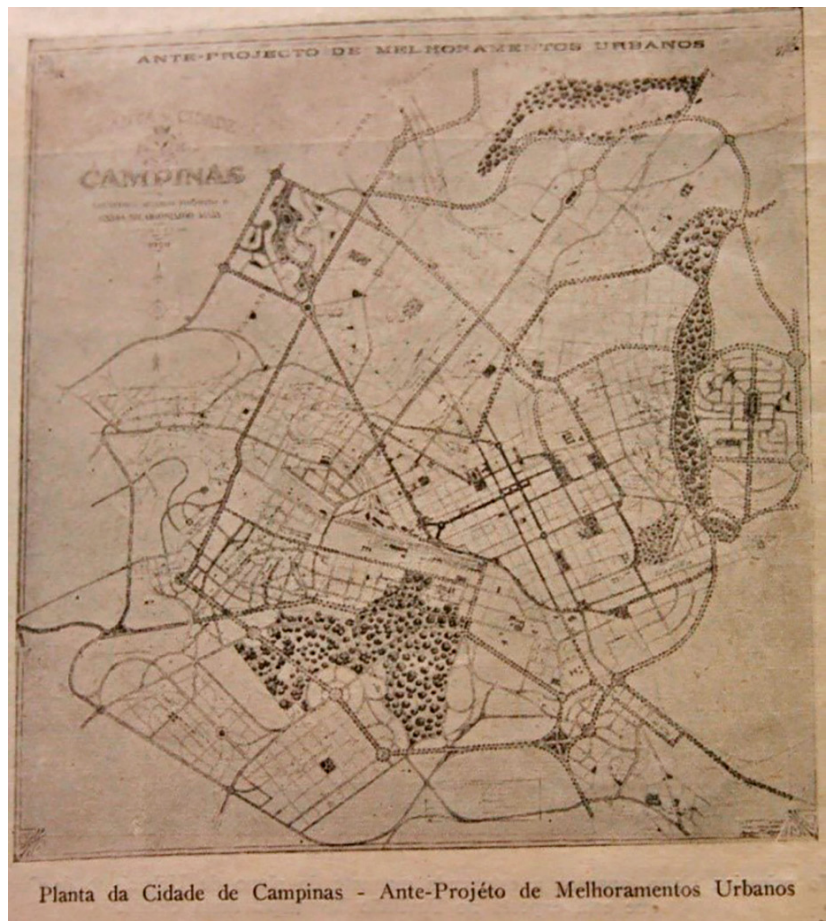

Figura 2 | Planta da Cidade de Campinas, de 1929, na qual foi anotado o anteprojeto do Plano de Melhoramentos Urbanos, elaborado pelo engenheiro Francisco Prestes Maia em 1934. Fonte: Revista Oficial da Exposição-Feira do Bi-Centenário de Campinas (1739-1939). São Paulo: J. Gozo, 1940. 
O plano proposto por Prestes Maia foi aprovado pela municipalidade por meio do Ato $n^{\circ} 118$, de 1938. Todavia, somente a remodelação viária foi oficializada, com alargamentos de ruas na área central da cidade, que incluía a demolição de edifícios históricos significativos da cidade em locais onde seriam construídos edifícios modernos (fig. 3 e 4).

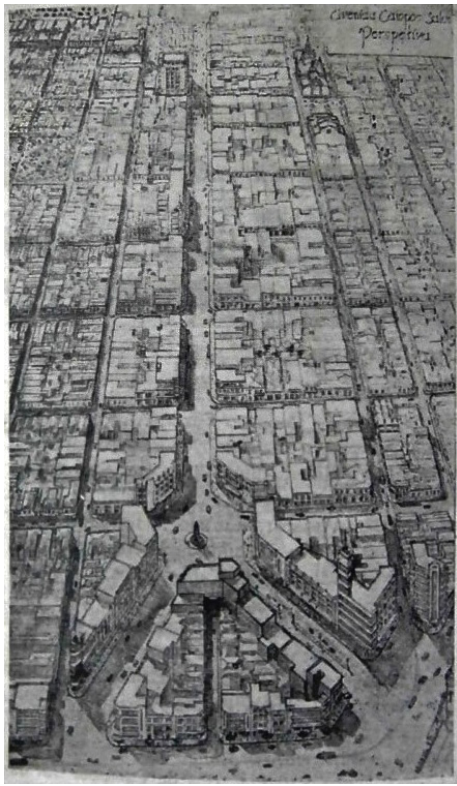

Figura 3 | Plano de Melhoramentos Urbanos. Perspectiva da avenida Campos Sales. Fonte: Revista Oficial da Exposição-Feira do Bi-Centenário de Campinas (1739-1939). São Paulo: J. Gozo, 1940. In.: KROGH; SALGADO; SOUZA. O papel das exposições na formação do urbanismo: a difusão do Plano de Melhoramentos de Campinas de Prestes Maia na exposição de 1939. Arq.Urb. USJT, número 17, setembro-dezembro de 2016. Disponível em: <http://www.usjt.br/arq.urb/numero-17/7-krogh-souza-salgado. pdf> Acesso em: 15 mar. 2018. 


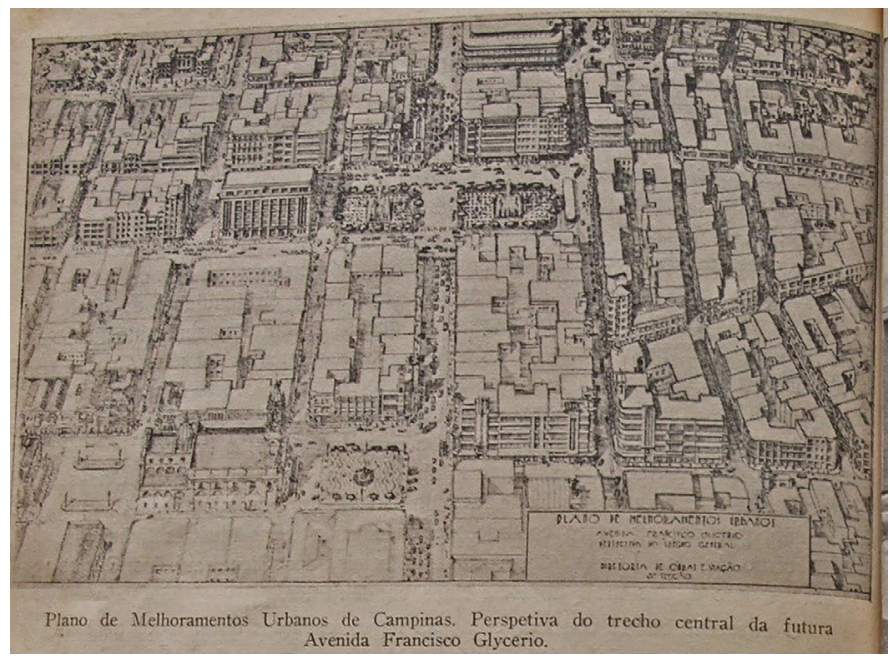

Figura 4 | Plano de Melhoramentos Urbanos. Perspectiva do trecho central da avenida Francisco Glicério. Fonte: Revista Oficial da Exposição-Feira do Bi-Centenário de Campinas (1739-1939). São Paulo: J. Gozo, 1940. In.: KROGH; SALGADO; SOUZA. O papel das exposições na formação do urbanismo: a difusão do Plano de Melhoramentos de Campinas de Prestes Maia na exposição de 1939. Arq.Urb. USJT, número 17, setembro-dezembro de 2016. Disponível em: <http://www.usjt.br/arq.urb/numero-17/ 7-krogh-souza-salgado.pdf> Acesso em: 15 mar. 2018.

O engenheiro Prestes Maia, no seu plano para Campinas, ainda apresentou uma proposta para o zonnig, que deveria ser implantado na área de expansão da cidade e estruturado a partir das unidades de vizinhança, baseado no projeto de Clarence Stein de 1928 para Radburn.

Antes da aprovação do denominado Plano de Melhoramentos Urbanos, mais um golpe viria paralisar todas as instân- 
cias do poder público no país. O golpe do Estado Novo, de 1937, oficializou a ditatura que Getúlio Vargas já vinha construindo desde 1930. Em relação às questões do urbanismo em Campinas, o debate foi brevemente interrompido, porém sem grandes alterações na estrutura da administração municipal e da Comissão de Urbanismo. A comissão, agora denominada Comissão de Melhoramentos Urbanos, só seria reestabelecida pelo prefeito nomeado João Alves dos Santos, por meio do Ato $n^{\circ}$ 115, de 18 de março de 1938.

No entanto, a ditadura varguista endureceu a tomada de decisões por parte das administrações municipais, que foram atreladas ao interventor federal nos estados com a criação dos Departamentos Administrativos ${ }^{15}$, que eram formados por uma burocracia de formação técnica.

No Brasil, durante a Era Vargas, as questões da intervenção no espaço urbano, entre outros aspectos, eram pensadas e discutidas nos conselhos municipais e pelos prefeitos nomeados por interventores federais, portanto eram também

15. Os Departamentos Administrativos ou Departamentos das Municipalidades foram criados em 1938, limitando a autonomia dos estados, inclusive financeiramente, pois empréstimos só poderiam ser contraídos sob autorização do presidente. Era uma maneira de controlar todos os aspectos que envolviam o poder local nos estados, bem como nos municípios. Embora o DASP tenha sido criado em 1938, o órgão foi formalizado por meio do Decreto-Lei $n^{\circ} 1.202$, de 8 de abril de 1939, que dispunha sobre a administração dos estados e municípios. Disponível em: <http://www2.camara.leg.br/legin/ fed/declei/1930-1939/decreto-lei-1202-8-abril-1939-349366-publicacaooriginal-1-pe.html> Acesso em: 03 jan. 2018. 
esferas de representação política. A partir da criação dos Departamentos Administrativos, os engenheiros municipais, mesmo que tivessem a incumbência da condução da implantação do plano, bem como a municipalidade, estavam subordinados tanto política como financeiramente ao poder federal, pois tudo era controlado pelo interventor federal e pelo DASP, em maior escala, no caso do estado de São Paulo.

Os agentes que atuavam na esfera pública em Campinas a partir da década de 1930, em sua maioria formada por técnicos, se aproximaram cada vez mais do governo da ocasião e adotavam medidas afinadas com os interesses da União. No nível estadual, os interesses da ditadura varguista passaram a ser representados a partir de 1938 por Adhemar de Barros, quando foi nomeado interventor em São Paulo, sendo que ele também nomeou Prestes Maia como prefeito da capital paulista no mesmo ano. Esse fato corrobora com a hipótese levantada, pois nesse momento o grupo oposicionista do qual Anhaia Mello fizera parte foi definitivamente afastado das discussões sobre a questão do urbanismo em Campinas.

Em Campinas, os interesses garantidos não foram de somente um ator/agente, ou o interesse pessoal de apenas um indivíduo, mas de todo um grupo de atores/agentes que tinham algo em comum: o interesse na transformação 
- que pode ser lida como modernização - da cidade, o que beneficiaria cada um dos membros desses grupos e, aqui se arrisca a dizer, o grupo inteiro. Esses grupos podem ser identificados como pertencentes tanto da burocracia técnica, atuante no âmbito estadual e municipal, como parte de um estado de exceção que buscava construir uma identidade nacional por meio da modernização do país como um todo, como das próprias empresas/escritórios de arquitetura e engenharia que atuaram na transformação física da cidade.

Dessa forma, pensar somente na escala individual, ou seja, nas ações de um prefeito ou um urbanista, ou mesmo um engenheiro dono de uma empresa, nesse caso, não pareceu correto, mas, sim, pensar nas ações de diversos atores, como, por exemplo, as Comissões de Urbanismo que foram organizadas para discutir as questões da remodelação da cidade e da própria elaboração do plano - Prestes Maia insistiu nesta questão quando participou de algumas reuniões da Comissão de Urbanismo de Campinas -, pode ser definida, como sugere Lepetit, "como a posição e extensão de um grupo unificado em torno de um sistema de representações partilhadas" (LEPETIT, 2001, p. 234).

\section{Referências}

À NAÇÃO. Manifesto do Partido Democrático contra o Interventor João Alberto. Disponível em: <http://www.arquivoestado.sp.gov.br/ 
uploads/acervo/textual/partido_democratico/BR_SP_APESP_IHGSP_ PD_098_001_001.pdf> Acesso em: 23 mai. 2018.

\section{ARQUIVO PÚBLICO DO ESTADO DE SÃO PAULO. Acervo do}

Partido Democrático de São Paulo. Disponível em: <http://www. arquivoestado.sp.gov.br/site/acervo/repositorio_digital/partido_democratico> Acesso em: 20 out. 2017.

A RESPOSTA do candidato democratico dr. Carlos A. Barbosa de Oliveira - Melhoramentos da cidade e transito urbano - Limpeza publica - Habitações proletárias - Outros assumptos. Noticias de Campinas. O Estado de São Paulo, 17 de outubro de 1928, p. 9. Disponível em: $<$ http://acervo.estadao.com.br/pagina/\#!/19281017-18059-nac-0004999-4-not/busca/planta+cadastral> Acesso em: 07 jan. 2018.

A SESSÃO de hontem - O sr. Belfort de Mattos apresenta um importante projecto sobre o urbanismo - Materia approvada na ordem do dia. O Estado de São Paulo, 06 de junho de 1929, p. 14. Disponível em: <http://acervo.estadao.com.br/pagina/\#!/19290606-18255-nac0014-999-14-not/busca/1929+CAMPINAS+Belfort> Acesso em: 07 jan. 2018.

BADARÓ, Ricardo. Campinas: o despontar da modernidade. Campinas: CMU/UNICAMP, 1996.

Blog Pró-Memória de Campinas. Disponível em: <http://pro-memoria-de-campinas-sp.blogspot.com.br/2007/01/memria-fotogrfica-dcada-de-1920.html> Acesso em: 18 ago. 2017.

BONFATO, Antonio Carlos. Macedo Vieira: ressonâncias do modelo cidade-jardim. São Paulo: Editara Senac, 2008.

CAMPINAS vai elaborar o seu plano de urbanismo. O Relatorio do Dr. Anhaia Mello, apresentado ao Sr. Prefeito Municipal. Correio Paulistano. Noticias do Interior. 23 de outubro de 1929. Ano 1929. Edição 23691. Hemeroteca Digital da Biblioteca Nacional. Disponível em: <http://memoria.bn.br/DocReader/Hotpage/HotpageBN.aspx?bib=090972_07\&pagfis=38166\&pesq=\&url=http://memoria.bn.br/ docreader\#> Acesso em: 20 jul. 2017.

CANO, Wilson. Da década de 1920 à década de 1930: transição rumo à crise e à industrialização no Brasil. Revista de Políticas Públicas. UFMA. São Luís, n. 16, p. 79-90, jan./jun. 2012. Disponível em: <http:// www.periodicoseletronicos.ufma.br/index.php/rppublica/article/ 
view/1179/932> Acesso em: 10 mar. 2018.

CARVALHO, José Murilo de. A vida política. In.: SCHAWARCZ, Lilia Moritz (dir.) et al. História do Brasil Nação: 1808-2010. A construção nacional: 1830-1889, volume 2. Rio de Janeiro: Objetiva, 2014.

FAUSTO, Boris. A revolução de 1930: historiografia e história. São Paulo: Companhia das Letras, 1997.

A vida política. In.: SCHAWARCZ, Lilia Moritz (dir.) et al. GOMES, Angela de Castro (coord.). História do Brasil Nação: 18082010. Olhando para dentro: 1930-1964, volume 4. Rio de Janeiro: Objetiva, 2014

FELDMAN, Sarah. Planejamento e zoneamento: São Paulo: 19471972. São Paulo: Editora da Universidade de São Paulo/Fapesp, 2005.

As Comissões de Planos da Cidade na Era Vargas. In: REZENDE, Vera F. (org.) Urbanismo na Era Vargas: a transformação das cidades brasileiras. Niterói: Editora da UFF, Intertexto, 2012.

FREY, Jean-Pierre. Les valises du progrès urbanistique. Modèles, échanges et transferts de savoir entre la France et l'Algérie. Les Cahiers d'EMAM [em ligne]. $n^{\circ}$ 20, 2010. Disponível em: <https://emam. revues.org/163\#bodyftn4> Acesso em: 11 out. 2017.

KROGH, Daniela da Silva Santos; SALGADO, Ivone; SOUZA, Rodrigo Henrique Busnardo. O papel das exposições na formação do urbanismo: a difusão do Plano de Melhoramentos de Campinas de Prestes Maia na exposição de 1939. Arq.Urb. USJT, número 17, setembro-dezembro de 2016. Disponível em: <http://www.usjt.br/arq.urb/numero-17/7-krogh-souza-salgado.pdf> Acesso em: 15 mar. 2018.

LEPETIT, Bernard. Por uma nova História Urbana. São Paulo: Editora da Universidade de São Paulo, 2001.

MAIA, Orosimbo. RELATÓRIO DOSTRABALHOS REALIZADOS PELA PREFEITURA DE CAMPINAS, durante o exercício de 1927 e apresentado á Câmara Municipal pelo Prefeito Orosimbo Maia. Aprovado em Sessão da Câmara de $1^{\circ}$ de fevereiro de 1928. Campinas: Typ. Casa Mascote-J. Ladeira, 1928.

RELATÓRIO DOSTRABALHOS REALIZADOS PELA PREFEITURA DE CAMPINAS, durante o exercício de 1929 apresentado à Câmara Municipal pelo Prefeito Orosimbo Maia. Aprovado em 
Sessão da Câmara de 5 de fevereiro de 1930. Campinas: Typ. da Casa Genoud, 1930.

MAIA, Francisco Prestes. Exposição Preliminar. In: RELATÓRIO DOS TRABALHOS REALIZADOS PELA PREFEITURA DE CAMPINAS, durante o exercício de 1934, apresentado ao Conselho Consultivo desta cidade e ao Departamento de Administração Municipal pelo prefeito José Pires Netto. Campinas: Linotypia da Casa Genoud Limitada, 1936.

MENDES, Ricardo. S.A.R.A Brasil: restituindo o Mapa Topográfico do Município de São Paulo. Informativo do Arquivo Histórico de São Paulo, ano 10, n 37, dez. 2014. Disponível em: <www.arquivohistoricosp.gov.br>

O PROJECTO sobre o urbanismo. O Estado de São Paulo, 22 de junho de 1929, p. 9. Disponível em: <http://acervo.estadao.com.br/pagina/\#!/19290622-18269-nac-0009-999-9-not/busca/CAMPINAS+URBANISMO> Acesso em: 21 mai. 2017.

O PROJECTO de Urbanismo. O Estado de São Paulo, 18 de setembro de 1929, p. 9. Disponível em: <http://acervo.estadao.com.br/pagina/\#!/19290918-18344-nac-0009-999-9-not/busca/CAMPINAS+URBANISMO> Acesso em: 14 set. 2017.

PRADO, Maria Lígia Coelho. A democracia ilustrada. O partido Democrático de São Paulo, 1926-1934. São Paulo: Editora Ática, 1986.

PRESIDÊNCIA DA REPÚBLICA. Constituição da República dos Estados Unidos do Brasil, 16 de julho de 1934. Disponível em: <http:// www.planalto.gov.br/ccivil_03/constituicao/constituicao34.htm> Acesso em: 24 set. 2017.

Revista Oficial da Exposição-Feira do Bi-Centenário de Campinas 1739-1939. São Paulo: J. Gozo, 1940.

SANTOS, Antonio da Costa. Campinas, das origens ao futuro: compra e venda de terra e água e um tombamento na primeira sesmaria da Freguesia de Nossa Senhora da Conceição das Campinas do Mato Grosso de Jundiaí (1732-1992). Campinas: Editora da UNICAMP, 2002.

SKIDMORE, Thomas E. Brasil: de Getúlio a Castello (1930-64). São Paulo: Companhia das Letras, 2010.

WOODWARD, James P. Regionalismo paulista e política partidária nos 
anos vinte. Revista de História da Universidade de São Paulo, $\mathrm{n}^{\circ}$ 150, 2004. Disponível em: <http://www.revistas.usp.br/revhistoria/ article/view/18977> Acesso em: 31 jul. 2017.

ZAKIA, Silvia Amaral Palazzi. Construção, arquitetura e configuração urbana de Campinas nas décadas de 1930 e 1940. O papel de quatro engenheiros modernos. Tese (Doutorado). São Paulo: FAU USP, 2012.

Uma nova paisagem urbana: Campinas dos anos 30 e 40.

São Paulo: Annablume, 2017.

Recebido em: 17/03/2018

Aprovado em: 23/05/2018 